\title{
STUdy OF THE INFLUENCE OF CUTTING TOOL GEOMETRY DURING Turning OF SUbMillimetre Nickel PARTS
}

\author{
Jindrich Sykora, Michal Povolny, Tomas Zatloukal, \\ Lubos Kroft \& Simon Syrovatka
}
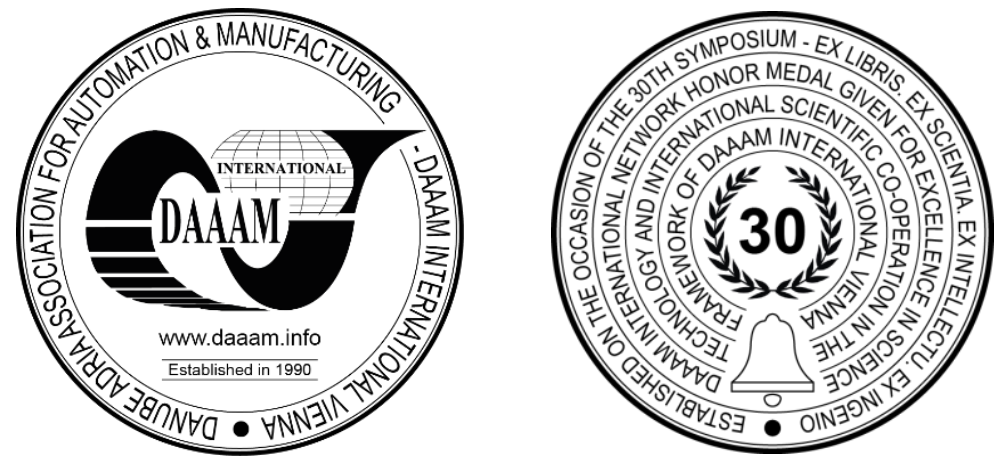

This Publication has to be referred as: Sykora, J[indrich]; Povolny, M[ichal]; Zatloukal, T[omas]; Kroft, L[ubos] \& Syrovatka, S[imon] (2021). Study of The Influence of Cutting Tool Geometry During Turning of Submillimetre Nickel Parts, Proceedings of the 32nd DAAAM International Symposium, pp.0395-0401, B. Katalinic (Ed.), Published by DAAAM International, ISBN 978-3-902734-33-4, ISSN 1726-9679, Vienna, Austria

DOI: $10.2507 / 32$ nd.daaam.proceedings.058

\begin{abstract}
The subject of this experiment was to produce parts with a specific shape and submillimetre elements. The parts represented components of commercial sparkplugs and the machined section was made of almost pure nickel. Relatively narrow required tolerance of parts (hundreds of micrometres), in combination with a large addition of material to the semi-finished product (several millimetres) and the required number of parts manufactured by one cutting insert for a very small time cycle led to the implementation of several tests to find ideal cutting inserts and conditions for production. All of the machining was done under dry conditions and the lowest possible machining time was also taken into account. Seven inserts with potentially suitable cutting-edge geometries were selected for testing. They were positive ISO C and ISO D inserts. After initial testing and determining the most suitable conditions for the most inserts, cutting forces during machining under constant conditions were measured. After the machining, each part was closely inspected by the microscope and all the critical dimensions, general shape and state of the surface were evaluated. In the course of the experiment, a significant effect of the geometry of the cutting insert was demonstrated. The best performing of used cutting inserts for these conditions was ISO D shape with a nose radius of $0.2 \mathrm{~mm}$ and a highly positive rake angle. In terms of the thin layer used, a TiAlN PVD coated insert seems to be the most ideal as it should significantly increase tool life. To verify this assumption extensive long-term testing would have to be done. These results confirm the importance of selecting appropriately positive geometry for turning small features in soft alloys along with the influence of nose radius with regard to depth of cut.
\end{abstract}

Keywords: Cutting forces; nickel; turning; cutting tool geometry

\section{Introduction}

The automotive industry is one of the main drivers of the economy today. The production of parts for this industry is now widespread and the automotive industry extends into a large range of other sectors. Here too, there is a considerable amount of innovation and new, unconventional solutions. The machining of such components must also be adapted to these new developments, both in terms of the machine and the tooling and machining strategy. 
The combination of non-traditional machining materials and workpiece shapes is now quite common. The problem arises when the component is really small in diameter but large in overall length. In engineering practice, we call such parts with a large slenderness ratio and machining them is always problematic. These are usually turned parts produced in large quantities. If this part needs to be machined in a material with high plasticity in a very short time with several other constraints, the problem becomes very complicated.

The machining of slender components brings with it many problematic factors to consider when designing a tool and machining strategy. Components with high slenderness ratios are prone to vibration, residual stress deformation or thermal deformation. All these phenomena are usually associated with dimensional instability or damage to the workpiece or tool. Another problem can be deformation caused by improper tool geometry. The choice of geometry of a given cutting tool has a dominant influence on the overall result and should be given considerable importance. [1], [2]

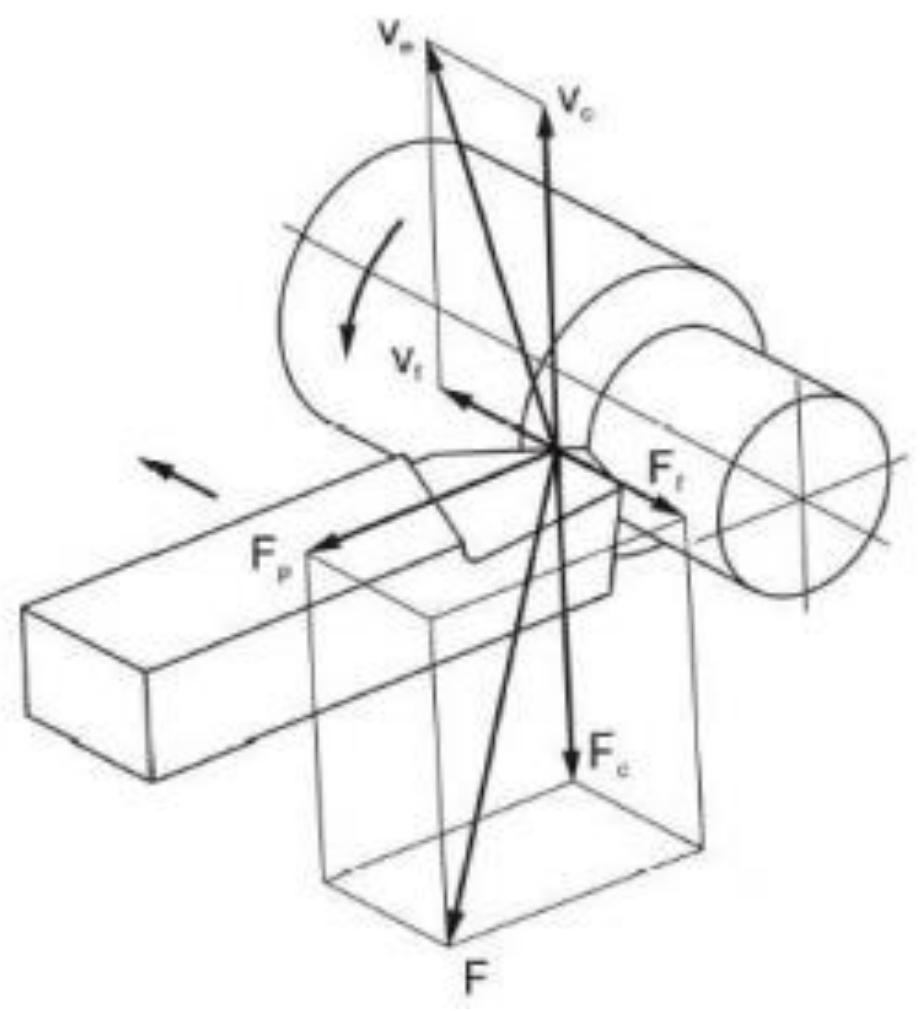

Fig. 1. Scheme of distribution of cutting forces during turning [6]

The geometry of the cutting edge, together with the cutting conditions and the material being machined, or its mechanical properties, gives us the initial force load. The total cutting force $\mathrm{F}$ required to cut the material must be greater than the resistance $\mathrm{R}$ given by the material properties and is influenced by a number of factors. However, the total cutting force is not very revealing for a deeper investigation of the machining process, so in most cases, it is necessary to measure the individual components as shown in Figure 1. These cutting force components are oriented according to an orthogonal coordinate system in a plane labelled by face, back and shear.

The total force can be calculated based on relation 1 .

$\mathrm{F}=\sqrt{F_{c}^{2}+F_{p}^{2}+F_{f}^{2}}[N]$

Each of these ingredients has a slightly different effect. From the point of view of part precision, the Fp component is essential - the feed force or radial force. Its value significantly influences the part's push-off from the cutting edge and thus especially the geometric accuracy of the part. Its value can be influenced by the appropriate choice of tool geometry, in particular the angle of the face and back and the angle of the main blade setting.

All the influences are described in Table 1 and illustrated in Figure 2. During the experiments described below, all components of the cutting force were measured and subsequently evaluated with respect to the qualitative results obtained. [3], [4], [5] 


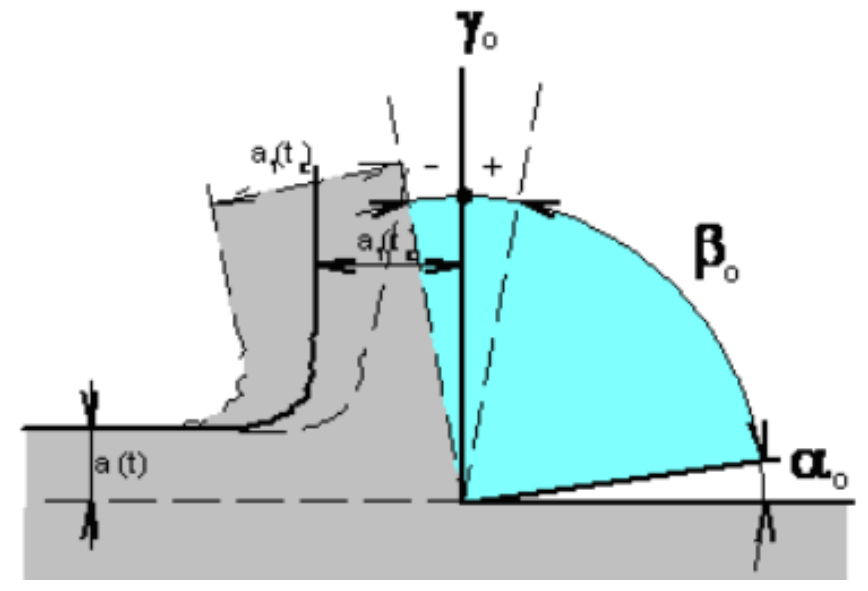

Fig. 2. Scheme of cutting angles in the cutting process [6]

\begin{tabular}{|c|c|}
\hline Individual cutting angles & Influence on the machining process \\
\hline \multirow{2}{*}{$\alpha_{0}$} & effect on the strength of the cutting edge \\
\cline { 2 - 2 }$\beta_{0}$ & effect on the friction between the back and the workpiece \\
\cline { 2 - 2 } & effect on the strength of the cutting edge \\
\hline \multirow{2}{*}{$\gamma_{0}$} & effect on thermal conductive properties \\
\cline { 2 - 2 } & effect on plastic deformation in the area of chip formation \\
\cline { 2 - 2 } & effect on friction between the chip and the cutting edge face \\
\hline
\end{tabular}

Table 1. Table the effect of cutting angles on the cutting process [6]

\subsection{Large-scale production of parts}

As already mentioned, the entire research was focused on turning very small parts for automotive applications. This meant in this case that the production of a large number of parts was expected. For this type of production, machines referred to as long-running machines (swiss type) are normally used. This type of machine is very suitable for the production of thin parts, as the part is continuously ejected from the spindle, thus eliminating most of the problematic phenomena occurring when machining parts with a large slenderness ratio. Unfortunately, this type of machine cannot be used in this experiment because the parts to be machined based on the results below are already in piece form after previous manufacturing operations and do not have a full-length rotational shape. [7]

Therefore, for the mass production of this type of workpiece, a machine with a vertical spindle was designed so that the part faces downwards after automatic foundation. Here, the parts are inserted and clamped by air and the whole machining cycle takes 8 seconds. This very short cycle time results in a clamping time of approximately 3 seconds after deducting the clamping time in which the part must be machined. With this in mind, an experiment was designed so that the entire part is machined to completion with only one pass of the tool.

The last limiting factor is that the parts will be machined without process fluid. The only possible cooling method is pressurized air. Due to the material to be machined, this is a rather complex issue, the solution to which is outlined in the next section of this article.

\section{Materials and methods}

\subsection{Workpiece and setup}

The workpiece used for this experiment was the centre electrode of a combustion engine spark plug. The goal is to create a shape on the end of the electrode that can be seen on Fig. 1 in less than 3 seconds under dry conditions as this operation will be a part of high volume automated production. The exact dimensional tolerances can not be revealed, but they are in the $0.05-0.1 \mathrm{~mm}$ range. This part has several specific characteristics that can make machining a complex problem. Firstly, the mechanical properties of the material are very close to a pure nickel (the exact alloy is classified), which means a high ductility, low tensile strength, and austenitic structure. Secondly, the machined features should not have any burrs, which is always a challenge when working with austenitic materials.

Lastly, due to the shape of the blank part, the overhang from the work holding must be at least $6 \mathrm{~mm}$, this combined with the diameter of the part means a 3 times diameter extension. Therefore, the lever is significant, and the cutting force and their distribution will have a large influence on the final shape of the part. 


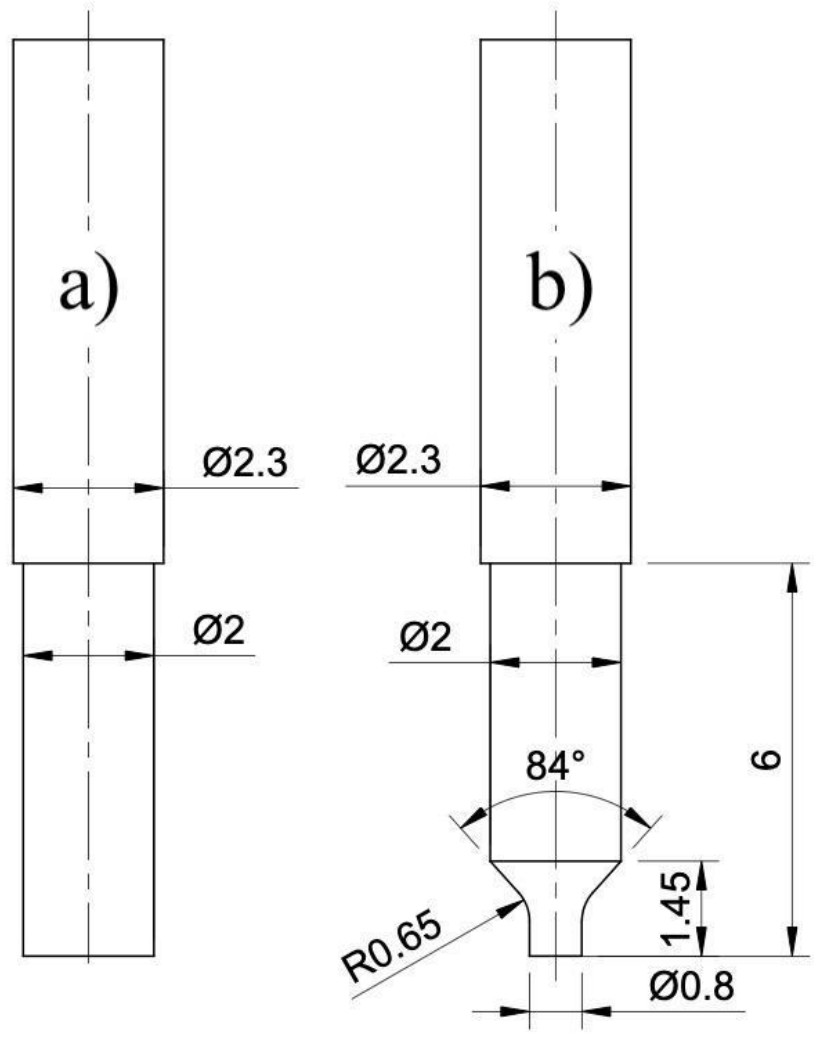

Fig. 3. Drawing of the blank workpiece (a) and the final part (b).

The parts were machined on an Emco MAXXTURN 25 lathe and held in an appropriate collet. Both of the tool holders SDJCL 1212F-11 and SCLCL 1212F-09 were held in a Kistler 9119AA2 dynamometer to measure the cutting forces. Suitable cutting conditions were determined as a result of pre-experiment, the feed rate per revolution was set to 0.07 $\mathrm{mm} / \mathrm{rev}$, the speed to $5000 \mathrm{rpm}$ and the maximum depth of cut was $0.6 \mathrm{~mm}$. After machining the parts were inspected on the Keyence VHX-6000 microscope. Before starting a cutting force measurement for each insert a test part was machined, measured and the inaccuracy was compensated in order to keep cutting conditions the same for each insert.

\subsection{Cutting tools}

The performance of inserts ISO C held in SCLCL 1212F-09 and ISO D held SDJCL 1212F-11 holder was tested. Inserts of varying geometries and coatings were sourced from one of the world's largest manufactures of cutting tools. The geometry of the cutting edge greatly influences the shearing action when material is removed and therefore, the resulting cutting forces and deformation of the workpiece. For this reason, the microgeometry of each insert was measured on Alicona ifm g4 (see Table 2).

\begin{tabular}{|c|c|c|c|c|c|}
\hline Insert & Grade & Edge radius $[\mu \mathrm{m}]$ & Rake angle $\left[{ }^{\circ}\right]$ & Clearance angle $\left.{ }^{\circ}{ }^{\circ}\right]$ & Nose radius [mm] \\
\hline DCGT - AS & IC 20 & 4 & 16 & 7 & 0.2 \\
\hline DCMT - PF & IC 807 & 43 & 5 & 7 & 0.2 \\
\hline DCGT - AS & IC 907 & 6 & 20 & 7 & 0.2 \\
\hline DCGT - AF & IC 20 & 5 & 13 & 7 & 0.4 \\
\hline CCGT - AS & IC 320 & 8 & 18 & 7 & 0.2 \\
\hline CCGT - AS & IC 520 & 11 & 20 & 7 & 0.2 \\
\hline CCMT - F3M & IC 807 & 39 & 12 & 7 & 0.2 \\
\hline
\end{tabular}

Table 2. The microgeometry of each tested insert was measured on Alicona ifm g4. 


\section{Experiments}

In initial tests, it was found that all ISO C inserts tend to undercut the initial few tenths of a millimetre of the cylindrical part, creating a significant radius at the edge. The part with the undesirable geometry is shown in figure 4. ISO D-shaped inserts with a significantly positive face geometry (AS designation) and a tip radius of $0.2 \mathrm{~mm}$ proved to be more suitable. These VBDs were subsequently tested at several variations of cutting speeds and feed rates. This comparison was made with the VBD - DCGT 11T302-AS IC907, which appears to be the most suitable for production. The IC907 grade is coated with a thin layer of TiAlN + TiN, which should provide longer cutting edge life.

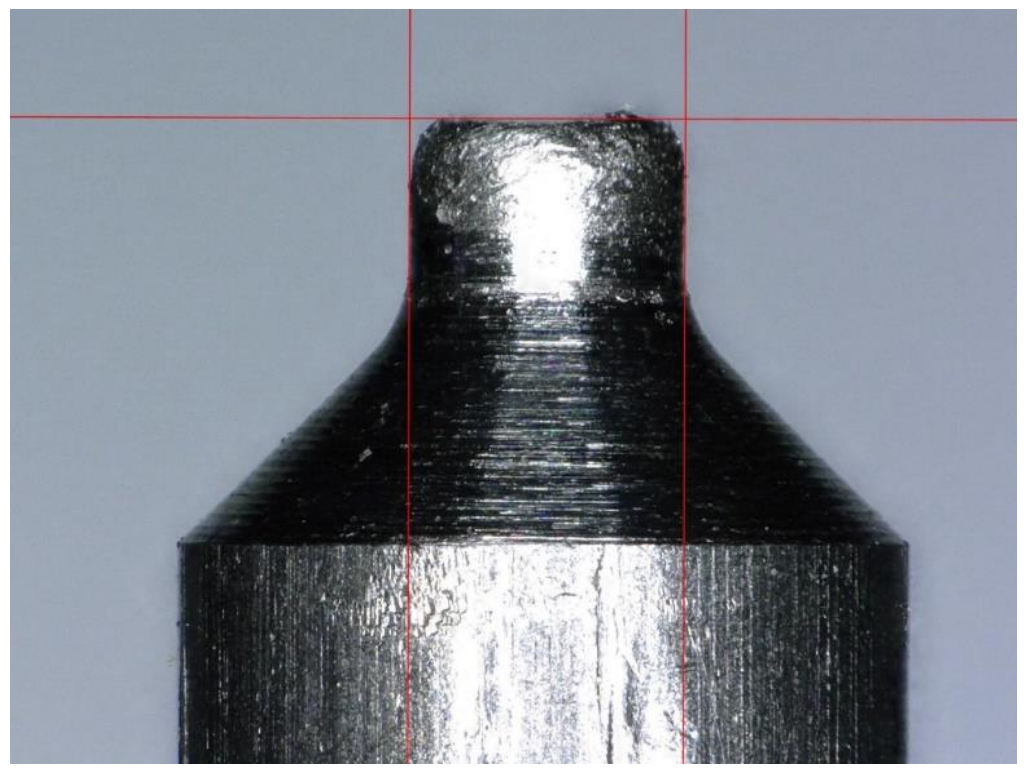

Fig. 4. Part machined with ISO C insert has unwanted curvature on the face

\subsection{Measurement of cutting forces}

The next step of the experiment was the measurement of cutting forces and their subsequent evaluation. Four measurements were recorded for all inserts, from which the resulting average and maximum machining forces were evaluated in the form of graphs (see figures below). The evaluation was performed based on the maximum cutting forces for Fp, Fc and Ff. The first graph describes the maximum cutting force components for each insert. The following graphs then show the cutting force components as a function of the edge radius on the insert. [8]

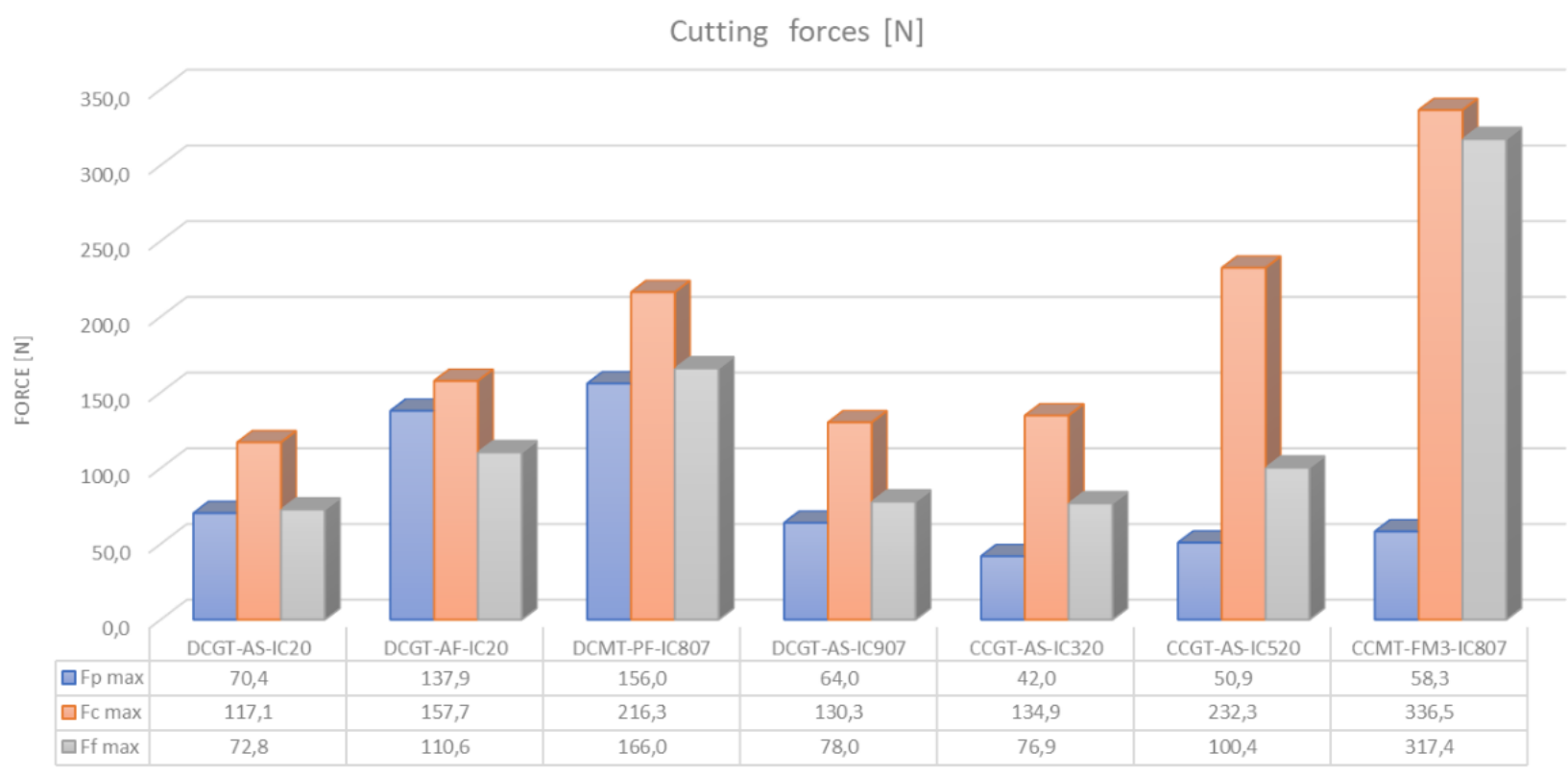

Fig. 5. Maximum values of measured forces 


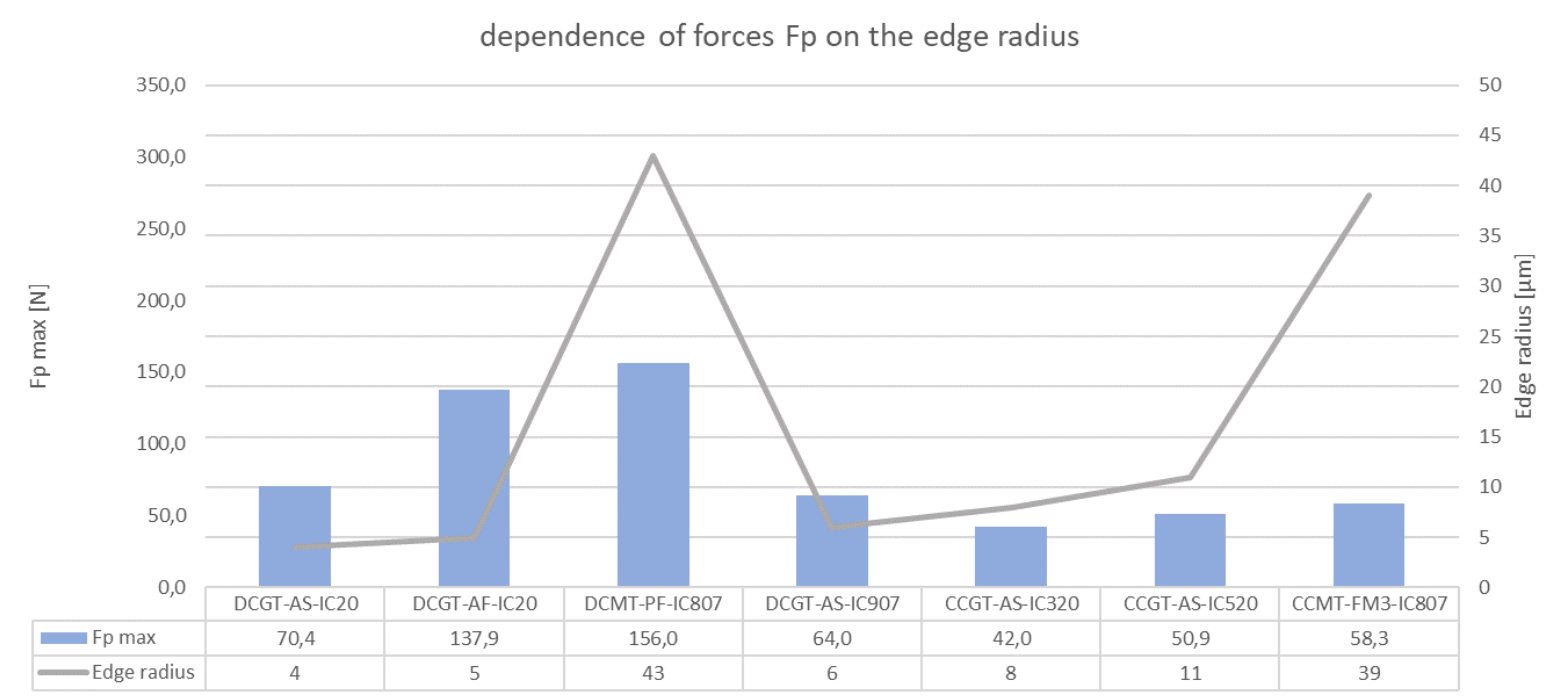

Fig. 6. Influence of cutting edge radius on Fp force

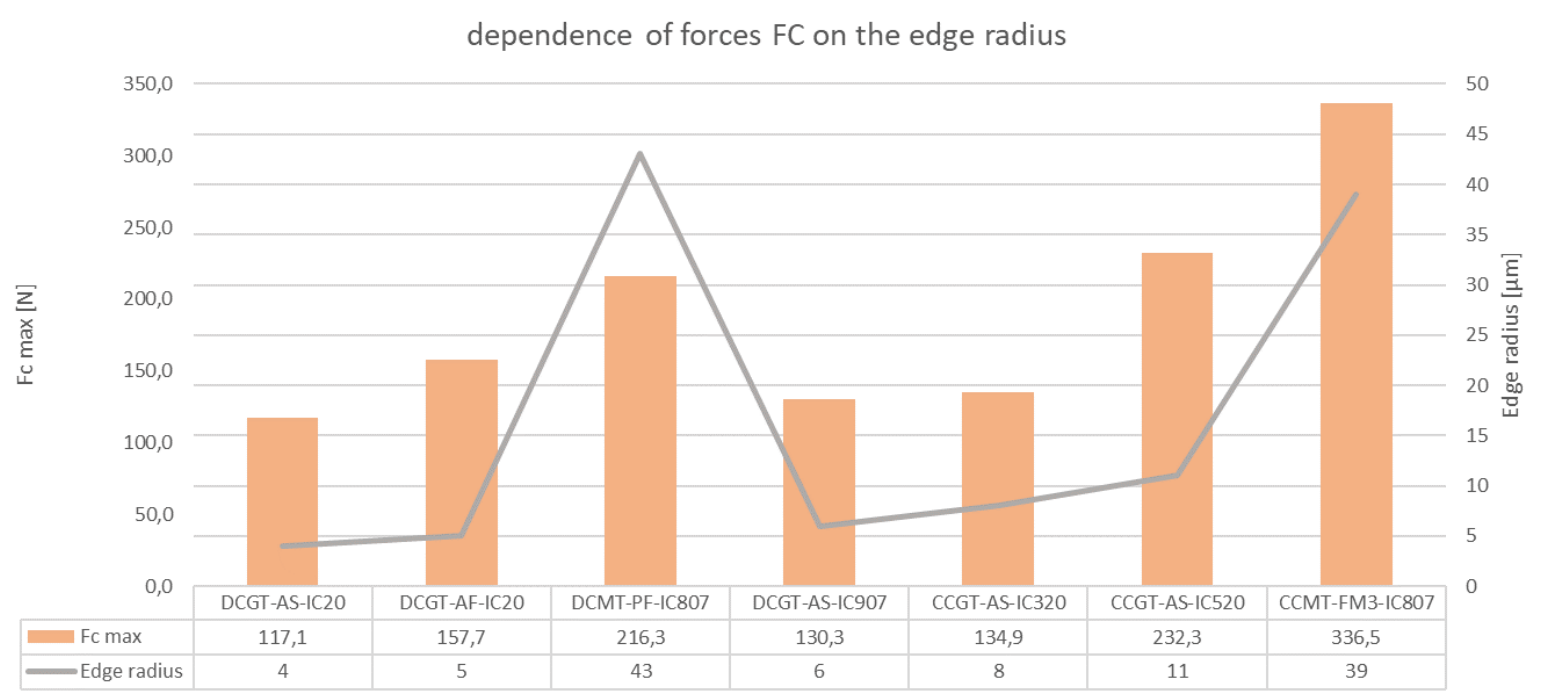

Fig. 7. Influence of cutting edge radius on Fc force

It is clear from the graphs that there is an increase in cutting forces when using a larger nose radius for the same DCGT-AS-IC20 (nose radius $0.2 \mathrm{~mm}$ ) vs DCGT-AF-IC20 (nose radius $0.4 \mathrm{~mm}$ ) inserts. The reason being that the DCGTAF-IC20 has a larger nose radius which effectively changes the side cutting edge angle when using small depths of cut. The large increase in forces is then evident when using inserts with a large edge radius, especially the DCMT-PF-IC807 and CCMT-FM3-IC807 types. This large difference in cutting forces only confirms the original finding that inserts with a larger nose radius but also with a larger edge radius tend to undercut. This results in large cutting forces and undesirable rounding at the face of the manufactured part. The graphs continue to show that the DCGT-AS-IC20 and DCGT-ASIC320 with a nose radius of R 0.2 and an edge radius of 4 and $6 \mu \mathrm{m}$ achieve the lowest cutting forces. This only confirms the results obtained during the measurement and inspection of the manufactured parts. When parts produced with these inserts achieved the most accurate dimensions and the best surface roughness parameters.

\section{Conclusion}

Research on machining strategy for machining the tip of a combustion spark plug was presented in this paper. This is a section with a large slenderness ratio produced in large batches from nearly pure nickel. This strategy will be implemented on a special single-purpose machine with no process fluid supply, with a single tool pass in a very short time of about 3 seconds. The problem was addressed mainly in terms of tooling and also the choice of suitable cutting conditions. Several conclusions can then be drawn from the experiments concerning the choice of tool geometry and the choice of cutting conditions. The choice of the edge radius is of fundamental importance. The larger the radius, the greater the cutting force and thus greater workpiece deformation and consequently increase in geometric inaccuracies. 
Furthermore, the size of the edge radius is very crucial from the micro-geometry point of view. The smaller the value of the edge radius the better the resulting surface roughness. The results of the experiments give us the most suitable combination of cutting tool, cutting conditions used and machining strategy is chosen. These results will then have to be verified during real production and other important parameters such as tool life will have to be measured. The result of the whole development is of considerable benefit not only to the customer but also to the research department and the results will be used as starting point in further research activities.

\section{Acknowledgements}

This article was created under the project SGS-2019-008: Research and Development for Innovation in the Field of Manufacturing Technology - Machining Technology III.

\section{References}

[1] Kaufnerova, A. \& Kutlwaser, J. (2019). The Course 'Practice of Experimental Methods in Machining', Annals of DAAAM for 2019 \& Proceedings of the 30th International DAAAM Symposium, Published by DAAAM International, Vienna, 2019, ISBN 978-3-902734-22-8

[2] Hronek, O. \& Zetek, M. (2017). The Influences of Cutting Edge Radius on Surface Roughness when Milling Nickel Alloy, Annals of DAAAM for 2017 \& Proceedings of the 28th International DAAAM Symposium, Published by DAAAM International, Vienna, 2017, ISBN 978-3-902734-11-2

[3] https://www.sandvik.coromant.com/cs-cz/knowledge/materials/pages/workpiece-materials.aspx, (2018). Machined materials, Accessed: 2021-10-10

[4] Cutting Conditions. (2017). https://eluc.kr-olomoucky.cz/verejne/lekce/1202, Accessed: 2021-10-10

[5] Brychta, J.; Čep, R.; Nováková, J. \& Petřkovská, L. (2007). Technology II - Part 1, Published by Ostrava VŠB-TU, 2007, ISBN 978-80-248-1641-8.

[6] VYŠATA, Jiří. Materials for the subject "engineering technology of machining" [online]. Pilsen, 2015 [cit. 2021 10-17]. University of West Bohemia.

[7] Elkins D. A., Huang N., and Alden J. M. (2004). 'Agile manufacturing systems in the automotive industry', International Journal of Production Economics, vol. 91, no. 3, pp. 201-214, doi: 10.1016/j.ijpe.2003.07.006.

[8] Hnatik, J; Kutlwaser, J \& Sklenicka, J (2016). iMachining Cutting Force Measurement, Proceedings of the 26th DAAAM International Symposium, pp.0955-0959, B. Katalinic (Ed.),Published by DAAAM International, ISBN 978-3-902734-07-5, ISSN 1726-9679, Vienna, Austria DOI: 10.2507/26th.daaam.proceedings.134 